\title{
Violência doméstica contra a mulher em Campo Grande, Mato Grosso do Sul: situação e realidade
}

\author{
Domestic violence against women in Campo Grande, Mato Grosso do Sul: situation and reality \\ Violencia doméstica contra las mujeres en Campo Grande, Mato Grosso do Sul: situación y \\ realidad
}

Iluska Lopes Schultz

ORCID: https://orcid.org/ 0000-0002-2212-2186 Secretaria Municipal de Saúde de Corumbá, Brasil E-mail: ilulschultz@gmail.com

Maria Auxiliadora de Souza Gerk ORCID: https://orcid.org/ 0000-0002-1056-3275 Universidade Federal de Mato Grosso do Sul, Brasil E-mail: enfadoragerk@gmail.com

Cristina Brandt Nunes

ORCID: https://orcid.org/ 0000-0003-2411-0717 Universidade Federal de Mato Grosso do Sul, Brasil E-mail: cbrandtnunes@gmail.com

Antonio Conceição Paranhos Filho ORCID: https://orcid.org/ 0000-0002-9838-5337 Universidade Federal de Mato Grosso do Sul, Brasil E-mail: toniparanhos@gmail.com

Waleria Menezes Barros

ORCID: https://orcid.org/ 0000-0003-3369-2130

Centro Universitário da Grande Dourados, Brasil E-mail: waleriabarros@gmail.com

Mayara Carolina Cañedo

ORCID: https://orcid.org/ 0000-0002-7232-1431

Núcleo Regional de Saúde de Dourados, Brasil E-mail: maycarolina@hotmail.com

Kassandhra Pereira Zolin

ORCID: https://orcid.org/ 0000-0003-2423-7769 Secretaria Municipal de Saúde de Campo Grande, Brasil E-mail: kassandhrazolin@gmail.com

Steven da Silva e Souza

ORCID: https://orcid.org/ 0000-0002-6168-1095 Governo do Estado de Mato Grosso do Sul, Brasil E-mail: steven.sss@pc.ms.gov.br

\begin{abstract}
Resumo
Objetivo: analisar a situação da violência doméstica contra a mulher em Campo Grande/Mato Grosso do Sul. Metodologia: Trata-se de uma pesquisa quantitativa e transversal. Esta pesquisa contém os dados disponibilizados pela Secretaria de Estado de Justiça e Segurança Pública de Mato Grosso do Sul, referentes aos casos notificados nos Boletins de Ocorrência, preenchidos na Primeira Delegacia de Atendimento Especializado à Mulher, de janeiro de 2010 a dezembro de 2014. A coleta de dados ocorreu no período de abril a agosto de 2015. Resultados: Este estudo evidenciou que, dos 11.084 casos de lesões corporais notificados, $59,8 \%$ foram registrados no âmbito intrafamiliar. Com relação aos estupros e homicídios ocorridos no contexto familiar, houve uma maior incidência de casos em mulheres pardas e com mais de 25 anos. Os bairros mais violentos da capital de Mato Grosso do Sul são os mais distantes e com mais unidades de rede de apoio social e de tratamento de saúde. Conclusão: a distribuição espacial dos casos de violência doméstica contra a mulher e das unidades de apoio ao enfrentamento da violência permitiu verificar a predominância da violência nas regiões urbanas com alta densidade populacional e de baixa renda, evidenciando relação entre a violência e as questões socioeconômicas.
\end{abstract}

Palavras-chave: Crimes contra as mulheres; Violência na família; Políticas públicas de saúde; Enfermagem.

\section{Abstract}

Objective: to analyze the situation of domestic violence against women in Campo Grande/Mato Grosso do Sul. Methodology: This is a quantitative and transversal research. This research contains data provided by the State Department of Justice and Public Security of Mato Grosso do Sul regarding cases reported in police reports, filled out 
at the First Police Station for Specialized Assistance to Women, from January 2010 to December 2014. The collection The data collection took place from April to August 2015. Results: This study showed that of the 11,084 reported cases of bodily injury $59.8 \%$ were registered within the family. In relation to rapes and homicides that occurred in the family context, there was a higher incidence of cases in brown women and over 25 years old. The most violent neighborhoods in the capital of Mato Grosso do Sul are the most distant and with the most units of social support network and health treatment. Conclusion: the spatial distribution of cases of domestic violence against women and support units to fight violence allowed to verify the predominance of violence in urban regions with high population density and low income, showing a relationship between violence and socioeconomic issues.

Keywords: Crimes against women; Violence in the family; Public health policies; Nursing.

\section{Resumen}

Objetivo: analizar la situación de la violencia intrafamiliar contra las mujeres en Campo Grande / Mato Grosso do Sul. Metodología: Se trata sobre una investigación cuantitativa y transversal. Esta investigación contiene datos proporcionados por el Departamento de Justicia y Seguridad Pública de Mato Grosso do Sul sobre casos denunciados en informes policiales, llenados en la Primera Comisaría de Atención Especializada a la Mujer, de enero de 2010 a diciembre de 2014. La recopilación de los datos se llevó a cabo de abril hacia agosto de 2015. Resultados: Este estudio mostró que de los 11.084 casos de lesiones corporales reportados, un 59,8\% se registraron dentro de la familia. En relación a las violaciones y homicidios ocurridos en el contexto familiar, hubo una mayor incidencia de casos en mujeres morenas y mayores de 25 años. Los barrios más violentos de la capital de Mato Grosso do Sul son los más distantes y con más unidades de red de apoyo social y tratamiento de salud. Conclusión: la distribución espacial de los casos de violencia intrafamiliar contra las mujeres y las unidades de apoyo para el combate a la violencia permitió verificar el predominio de la violencia en regiones urbanas con alta densidad poblacional y bajos ingresos, mostrando una relación entre violencia y aspectos socioeconómicos.

Palabras clave: Delitos contra la mujer; Violencia en la familia; Políticas de salud pública; Enfermería.

\section{Introdução}

Toda mulher deveria ter como direito garantido a liberdade de desfrutar do seu lar, sabendo que é um ambiente seguro para ela. No entanto, essa realidade ainda é um privilégio de gênero (Campos, Tchalekian \& Paiva, 2020). A violência de gênero consiste em qualquer tipo de violência física, social ou simbólica, contra indivíduos em virtude do seu sexo, identidade de gênero ou orientação sexual. A violência masculina contra mulheres é a mais prevalente, principalmente a doméstica (Sardenberg \& Tavares, 2016).

A violência doméstica contra a mulher (VDCM) é um problema de saúde pública com raízes histórico-culturais, ou seja, comportamentos violentos naturalizados pelo senso comum (Acosta, et al., 2018). Além de que existem os estigmas estabelecidos entre homens e mulheres em que o homem é o provedor e a mulher a cuidadora da casa e da família (Silva, et al., 2020). Ademais, a violência intrafamiliar causa danos para crianças e adolescentes, pois a criança que testemunha a agressão à sua mãe é vítima de violência psicológica, podendo apresentar depressão, agressividade, isolamento e diminuição da autoestima (Reis, Prata \& Parra, 2018).

No Brasil, um estudo transversal realizado com dados do Sistema de Informação de Agravos de Notificação (Sinan) no período de 2011 a 2017, evidenciou que, dos 454.984 casos de violência de homens contra mulheres ( $\geq 15$ anos de idade), $62,4 \%$ estavam relacionados à violência por parceiro íntimo (VPI) (Mascarenhas, et al., 2020). Outro estudo do tipo inquérito domiciliar realizado em João Pessoa (PB) no período de agosto de 2013 a dezembro de 2015 evidenciou que existe relação entre a violência doméstica contra a mulher e a qualidade de vida, quando consideradas as seguintes variáveis: relações sociais, ou seja, uma mulher que usufrui de uma rede de apoio social tem menos chance de sofrer violência doméstica; segurança e proteção, pois, por mais que existam leis, as mulheres ainda se sentem inseguras de denunciar o agressor; e a oferta de tratamento médico, pois a mulher espera ao procurar as instituições de saúde ser ouvida e acolhida pelo profissional (Lucena, et al., 2017).

Estudo realizado em dois hospitais do Sul do país com 100 enfermeiras, cujo objetivo era analisar a estrutura e os conteúdos das representações sociais destas acerca da violência doméstica contra a mulher, demonstrou que a agressão física é a forma mais comum de violência reconhecida pelas referidas profissionais, evidenciando que a assistência de enfermagem 
possui um caráter clínico e que não contempla a subjetividade das mulheres (Acosta, et al., 2018). Outro estudo realizado com 15 profissionais de saúde que objetivou identificar, a partir do discurso dos indivíduos que trabalham em serviços de proteção a crianças e adolescentes, práticas que silenciavam a violência intrafamiliar mostrou que as atividades desenvolvidas pelos profissionais do estudo podem contribuir para a reincidência da violência intrafamiliar e que se limitam ao tratamento das lesões e agravos físicos (Schek, et al., 2018).

A realização deste estudo justifica-se pela importância de entender a violência de gênero, neste caso, a violência contra a mulher pelos profissionais de saúde e pelos serviços de escuta, denúncia e notificação (Souza, et al., 2021). Sua relevância pauta-se na necessidade de assistência que a mulher demanda e que nem sempre é fornecida por sua rede de apoio, levando-a a procurar os serviços de saúde a fim de conseguir dos profissionais o suporte necessário (Amarijo, et al., 2020). Em vista disso, a questão de pesquisa foi assim delineada: Qual é a situação da violência doméstica contra a mulher em um centro urbano? Desse modo, objetivou-se analisar a situação da violência doméstica contra a mulher em Campo Grande/Mato Grosso do Sul (MS). Essas informações podem contribuir para o quadro nacional da compreensão do problema.

\section{Metodologia}

Trata-se de uma pesquisa quantitativa e transversal, realizada em Campo Grande, MS. O município está localizado na porção central do MS; é a capital desde 1978, possui uma área de 8.082,978 km² e uma população estimada de 786.797 habitantes (IBGE, 2019).

A capital é composta por sete regiões urbanas: Anhanduizinho, Bandeira, Centro, Imbirussu, Lagoa, Prosa e Segredo, as quais são formadas por 77 bairros. A região urbana da Anhanduizinho é a mais populosa, com 185.558 habitantes e possui 14 bairros (PLANURB, 2016).

Para a realização de atendimentos às mulheres em situação de violência em Campo Grande (MS) são disponibilizados os seguintes serviços: 132 locais de Assistência Social; uma Casa da Mulher Brasileira, dez Delegacias da Polícia Civil (sendo $1^{\text {a }}$ DEAM), 101 Unidades de Saúde, dez Terminais de Transporte Coletivo (urbano) e um Terminal de Transporte Coletivo (rodoviário) (PLANURB, 2016).

Esta pesquisa contém os dados disponibilizados pela Secretaria de Estado de Justiça e Segurança Pública de MS (SEJUSP), referentes aos casos notificados nos Boletins de Ocorrência (BO), preenchidos na Primeira Delegacia de Atendimento Especializado à Mulher de Campo Grande/MS (1ª DEAM), de janeiro de 2010 a dezembro de 2014.

A coleta de dados ocorreu no período de abril a agosto de 2015. Os BOs, gerados a partir do atendimento às mulheres na $1^{\text {a }}$ DEAM, ficam armazenados no Sistema Integrado de Gestão Operacional (SIGO) que é um sistema de acesso restrito, necessitando senha pessoal e intransferível, disponível apenas para os funcionários da SEJUSP. Desta forma, os dados foram acessados por funcionário autorizado pela própria SEJUSP, que repassou as informações à pesquisadora para uso exclusivo na pesquisa, resguardando o anonimato das mulheres que sofreram violência. Dentre os dados solicitados à SEJUSP, para a caracterização do perfil socioeconômico das mulheres em situação de violência, foram repassados apenas os seguintes: idade, cor da pele e local da ocorrência. Quanto à variável cor da pele, vale ressaltar que é autor referida e, caso não seja mencionada, não é registrada.

A avaliação da associação entre o ano em que a violência ocorreu e as seguintes variáveis: faixa etária, cor da pele, região urbana, dia da semana e faixa de horário, foi realizada por meio do teste do qui-quadrado. Os demais resultados deste estudo foram apresentados na forma de estatística descritiva ou na forma de tabelas e figuras. A análise estatística foi realizada por meio do programa estatístico SigmaPlot, versão 12.5, considerando um nível de significância de 5\%.

Para a análise do padrão espacial os dados referentes aos tipos de violência doméstica e sobre as redes de apoio ao enfrentamento da violência foram importados para um Sistema de Informações Geográficas (SIG), livre e gratuito, 
denominado QGIS Essen (QGIS DEVELOPMENT TEAM, 2016). Os dados foram agrupados por regiões urbanas do município pesquisado.

Desta forma, foram mapeadas as unidades de serviço que realizam suporte à mulher em situação de violência doméstica conforme os dados disponibilizados pela Prefeitura Municipal de Campo Grande por meio do site do Sistema Municipal de Geoprocessamento (SIMGEO). Para a obtenção dos endereços das Delegacias da Polícia Civil foi necessário realizar uma busca online utilizando a base de dados do Google; para tanto, os endereços foram transformados em pares de coordenadas geográficas no Google Earth. Posteriormente, foi elaborada a espacialização dessas unidades de apoio em um arquivo vetorial em formato de shapefile de pontos.

O shapefile é um formato de arquivo vetorial, legível por diversos SIGs, que pode ser composto por pontos, linhas ou polígonos, que carregam além da informação gráficas, diversos metadados que permitem sua representação no espaço; ou seja, não é apenas um desenho geométrico, mas uma representação da real localização dos elementos no mundo real.

A pesquisa foi aprovada pelo CEP/UFMS sob CAEE $\mathrm{n}^{\circ} 37852214.2 .0000 .0021$ e parecer $\mathrm{n}^{\circ} 890.305$ de 02 de novembro de 2014. O estudo faz parte de um projeto maior intitulado "A situação da violência contra a mulher em Campo Grande- MS”. Por tratar-se de pesquisa em dados secundários foi solicitada dispensa do Termo de Consentimento Livre e Esclarecido (TCLE) ao Comitê de Ética em Pesquisa com Seres Humanos da Universidade Federal de Mato Grosso do Sul (CEP/UFMS), bem como foi encaminhado o Termo de Compromisso de Manuseio de Informações de Banco de Dados assinado pela pesquisadora principal.

\section{Resultados}

Entre os anos de 2010 e 2014, foram registrados 12.709 casos de violência contra a mulher no âmbito geral, em Campo Grande (MS), de acordo com a Secretaria de Estado de Justiça e Segurança Pública (SEJUSP). Destes, os casos de estupro foram 11,8\% ( $\mathrm{n}=1.506)$, os homicídios dolosos foram $0,9 \%(\mathrm{n}=119)$ e os casos de lesão corporal foram $87,2 \%(\mathrm{n}=11.084)$. Estes resultados estão ilustrados na Figura 1. 
Figura 1: Percentual de casos de violência contra a mulher, de acordo com o tipo de violência registrada em Campo Grande, MS, entre os anos de 2010 e 2014. Campo Grande/MS, 2016.

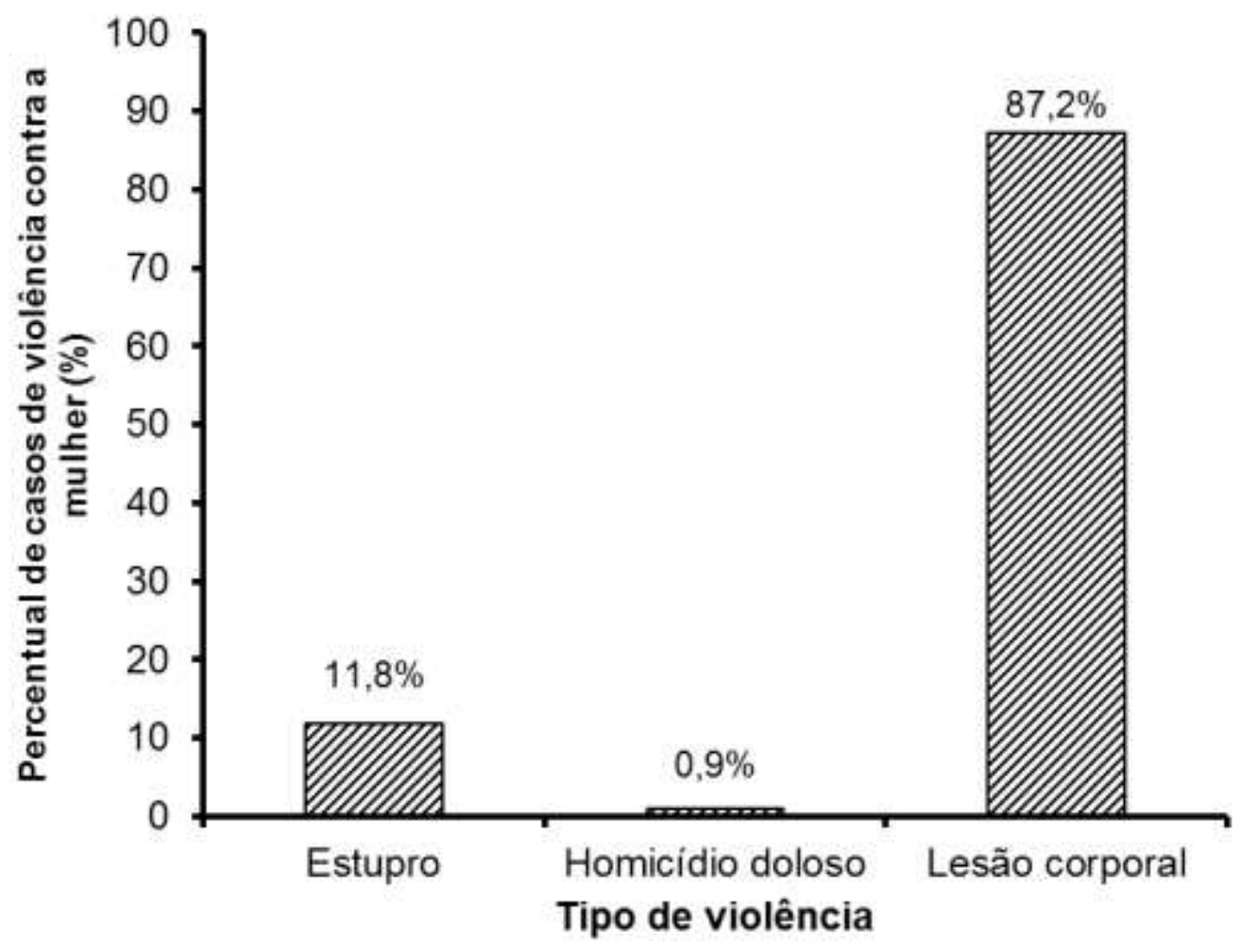

Fonte: Elaboração própria.

Para a SEJUSP a violência doméstica é aquela que ocorre em âmbito familiar conforme definição contida na Lei ${ }^{\circ}$ 11.340/2006 (BRASIL, 2006). Segundo a OMS (2021), a violência perpetrada por marido ou parceiro íntimo do sexo masculino (física, sexual ou psicológica) é a forma mais generalizada de violência contra as mulheres em todo o mundo.

Dos 1.506 casos de estupro, 119 de homicídio doloso e 11.084 de lesão corporal registrados, 7,4\% (n=111), 12,6\% $(n=15)$ e $59,8 \%(n=6.630)$ deles ocorreram, respectivamente, no âmbito familiar, enquanto que os demais ocorreram em outros locais.

O número de casos de estupro, homicídio doloso e lesão corporal infringido às mulheres no âmbito familiar e geral, entre os anos de 2010 e 2014, foram apresentados em números absolutos para melhor representatividade e estão ilustrados nas Figuras 2, 3 e 4, respectivamente. 
Figura 2: Casos de estupro entre as mulheres no geral e no âmbito familiar, entre os anos de 2010 e 2014 , registrados em Campo Grande, MS. Campo Grande/MS, 2016.

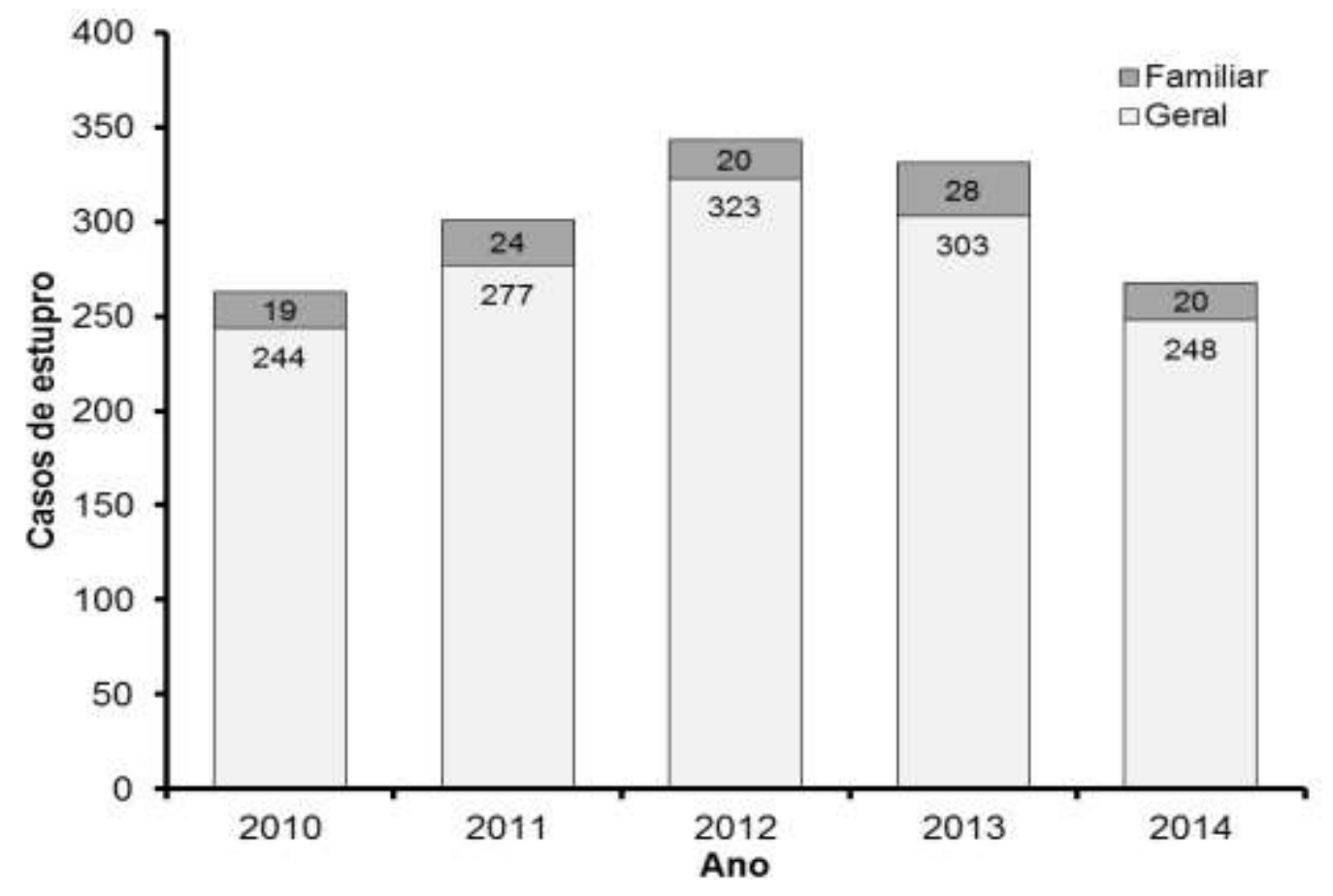

Fonte: Elaboração própria.

Figura 3: Casos de homicídio doloso entre as mulheres no geral e no âmbito familiar, entre os anos de 2010 e 2014 , registrados em Campo Grande, MS. Campo Grande/MS, 2016.

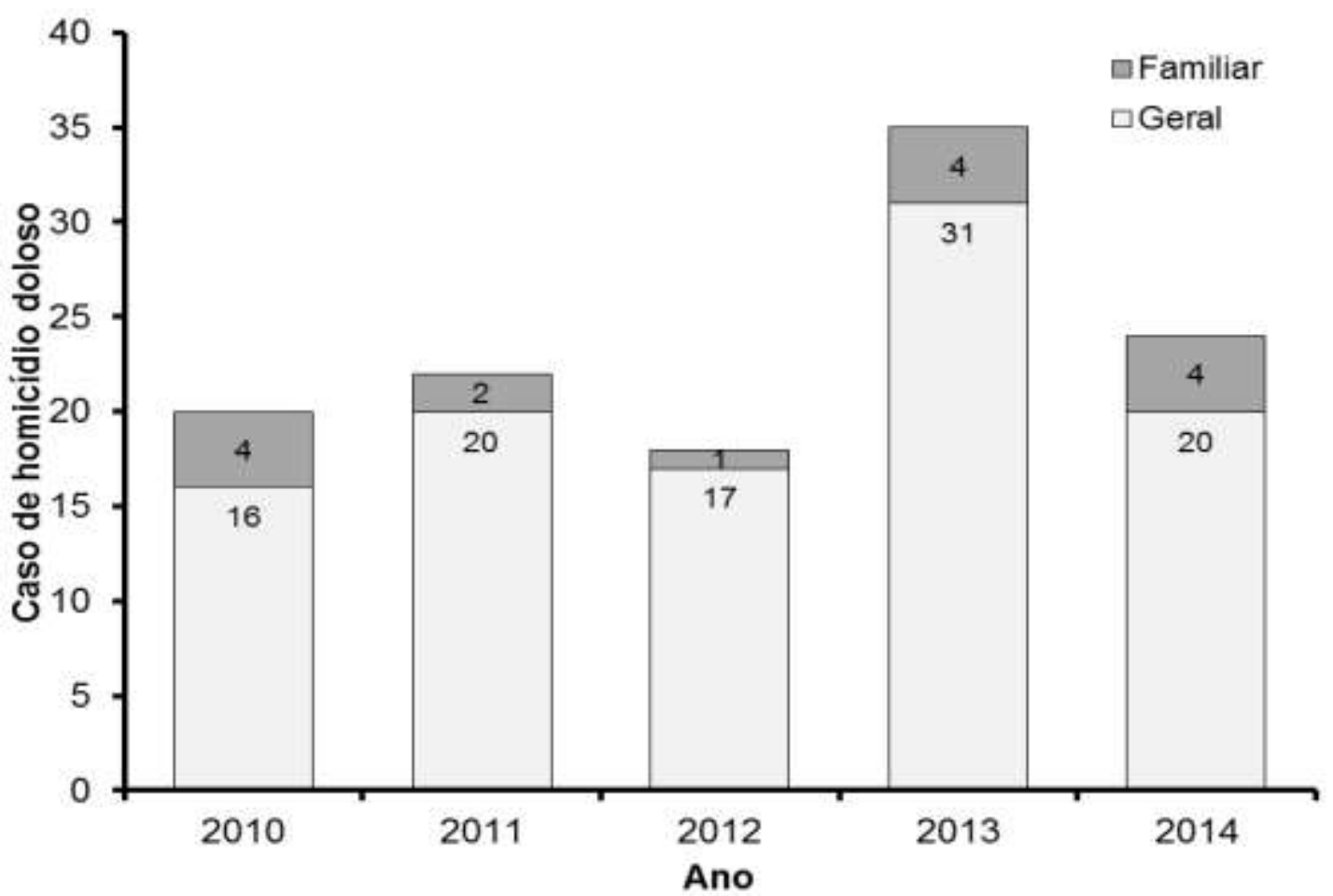

Fonte: Elaboração própria. 
Figura 4: Casos de lesão corporal sofrido por mulheres no geral e no âmbito familiar, entre os anos de 2010 e 2014 , registrados em Campo Grande, MS. Campo Grande/MS, 2016.

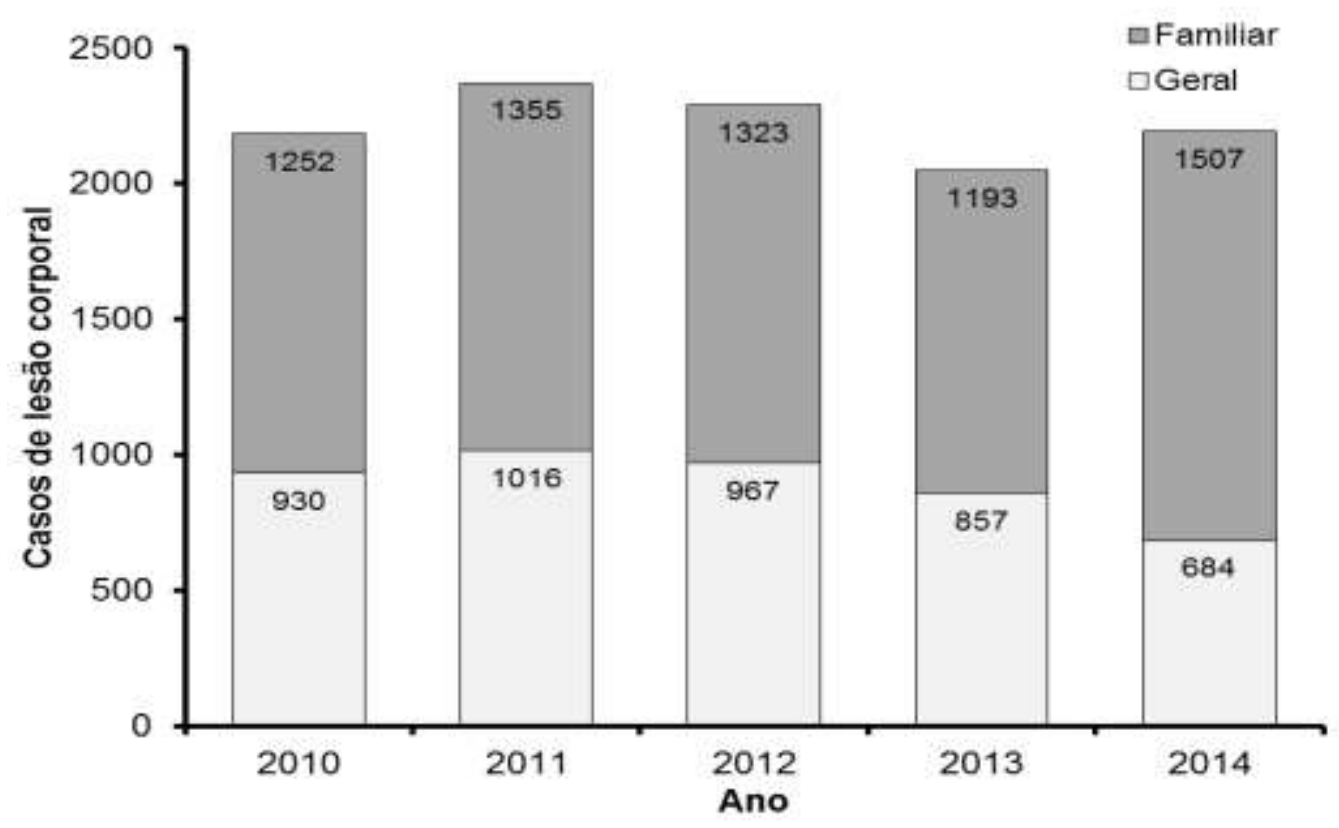

Fonte: Elaboração própria.

Na Tabela 1, estão apresentados os casos de estupro entre as mulheres no âmbito familiar, ano a ano, entre os anos de 2010 a 2014 e também no total, de acordo com a faixa etária, cor da pele, região urbana, dia da semana e faixa de horário.

No âmbito familiar, a maior parte dos estupros ocorreu contra as mulheres com idade superior a 25 anos $(65,8 \%$ $\mathrm{n}=73)$ e pardas $(70,5 \%-\mathrm{n}=62)$. Estes estupros ocorreram em todas as regiões urbanas da cidade, nos distintos dias da semana, sendo que a faixa de horário entre $18 \mathrm{~h}$ e $06 \mathrm{~h} 59 \mathrm{~min}$ foi a que apresentou mais ocorrências deste tipo de violência (60,6\% n=60). Em relação aos casos de estupro, no âmbito familiar, não foi observada associação entre o ano e as demais variáveis avaliadas neste estudo (valor de p variando entre 0,207 e 0,423).

Os homicídios dolosos no âmbito familiar ocorreram principalmente contra mulheres com idade superior a 25 anos de idade $(86,7 \%$ - $n=13)$ e pardas $(73,3 \%$ - $n=11)$. No centro da cidade não foi registrado nenhum caso deste tipo de violência durante o período estudado. No entanto, todas as demais regiões urbanas apresentaram casos de homicídio dolosos no âmbito familiar, distribuídos nos diversos dias da semana, sendo que 46,7\% ( $\mathrm{n}=7$ ) destes casos ocorreram entre 18h e 23h59min. Estes resultados estão apresentados na Tabela 2. Em relação aos casos de homicídio doloso, no âmbito familiar, não foi observada associação entre o ano e as demais variáveis avaliadas neste estudo (valor de p variando entre 0,197 e 0,758).

Os resultados referentes aos casos de lesão corporal causada em mulheres no âmbito familiar, entre os anos de 2010 e 2014, e no total, de acordo com a faixa etária, cor da pele, região urbana, dia da semana e faixa de horário, estão apresentados na Tabela 3.

No âmbito familiar foi observado mais casos de lesão corporal entre mulheres com mais de 25 anos de idade (64,3\% $\mathrm{n}=4266)$ e pardas $(64,2 \%$ - $\mathrm{n}=3568)$. Este tipo de violência ocorreu em todas as regiões da cidade, sendo que no sábado e no domingo foram os dias onde mais ela ocorreu (sábado: 21,3\% - n=1302; domingo: 24,9\% - n=1527). Em relação ao horário, este tipo de violência ocorreu mais entre $12 \mathrm{~h}$ e 23h59min $(68,2 \%$ - n=4175). Em relação aos casos de lesão corporal, no âmbito familiar, não foi observada associação entre o ano e as demais variáveis avaliadas neste estudo (valor de p variando entre 0,105 e 0,890$)$. 
Tabela 1: Casos de estupro entre as mulheres no âmbito familiar, entre os anos de 2010 e 2014, e de acordo com a faixa etária, cor da pele, região urbana, dia da semana e faixa de horário, registrados em Campo Grande, MS. Campo Grande/MS, 2016.

\begin{tabular}{|c|c|c|c|c|c|c|}
\hline $\begin{array}{c}\text { Estupro } \\
\text { (Familiar) }\end{array}$ & $\begin{array}{c}2010 \\
(n=19)\end{array}$ & $\begin{array}{c}2011 \\
(n=24)\end{array}$ & $\begin{array}{c}\text { Ano } \\
2012 \\
(n=20)\end{array}$ & $\begin{array}{c}2013 \\
(n=28)\end{array}$ & $\begin{array}{c}2014 \\
(n=20)\end{array}$ & $\begin{array}{l}\text { Total } \\
(111)\end{array}$ \\
\hline \multicolumn{7}{|c|}{ Faixa etária $(p=0,396)$} \\
\hline Menor que 12 & $0,0(0)$ & $4,2(1)$ & $5,0(1)$ & $0,0(0)$ & $5,0(1)$ & $2,7(3)$ \\
\hline Entre 12 e 17 & $0,0(0)$ & $0,0(0)$ & $10,0(2)$ & $7,1(2)$ & $15,0(3)$ & $6,3(7)$ \\
\hline Entre 18 e 25 & $10,5(2)$ & $33,3(8)$ & $30,0(6)$ & $25,0(7)$ & $25,0(5)$ & $25,2(28)$ \\
\hline Maior que 25 & $89,5(17)$ & $62,5(15)$ & $55,0(11)$ & $67,9(19)$ & $55,0(11)$ & $65,8(73)$ \\
\hline \multicolumn{7}{|c|}{ Cor da Pele $(p=0,423)$} \\
\hline Branca & $12,5(2)$ & $28,6(6)$ & $38,9(7)$ & $30,4(7)$ & $20,0(2)$ & $27,3(24)$ \\
\hline Preta & $6,3(1)$ & $0,0(0)$ & $0,0(0)$ & $0,0(0)$ & $10,0(1)$ & $2,3(2)$ \\
\hline Amarela & $0,0(0)$ & $0,0(0)$ & $0,0(0)$ & $0,0(0)$ & $0,0(0)$ & $0,0(0)$ \\
\hline Parda & $81,3(13)$ & $71,4(15)$ & $61,1(11)$ & $69,6(16)$ & $70,0(7)$ & $70,5(62)$ \\
\hline Outras & $0,0(0)$ & $0,0(0)$ & $0,0(0)$ & $0,0(0)$ & $0,0(0)$ & $0,0(0)$ \\
\hline Não Informado & 3 & 3 & 2 & 5 & 10 & 23 \\
\hline \multicolumn{7}{|c|}{ Região Urbana $(p=0,247)$} \\
\hline Centro & $11,8(2)$ & $9,5(2)$ & $0,0(0)$ & $8,0(2)$ & $0,0(0)$ & $6,7(6)$ \\
\hline Segredo & $17,6(3)$ & $14,3(3)$ & $31,6(6)$ & $4,0(1)$ & $25,0(2)$ & $16,7(15)$ \\
\hline Prosa & $0,0(0)$ & $4,8(1)$ & $0,0(0)$ & $12,0(3)$ & $0,0(0)$ & $4,4(4)$ \\
\hline Bandeira & $29,4(5)$ & $14,3(3)$ & $26,3(5)$ & $12,0(3)$ & $0,0(0)$ & $17,8(16)$ \\
\hline Anhanduizinho & $11,8(2)$ & $28,6(6)$ & $26,3(5)$ & $32,0(8)$ & $62,5(5)$ & $28,9(26)$ \\
\hline Lagoa & $11,8(2)$ & $23,8(5)$ & $5,3(1)$ & $24,0(6)$ & $12,5(1)$ & $16,7(15)$ \\
\hline Imbirussu & $15,8(3)$ & $4,8(1)$ & $10,5(2)$ & $8,0(2)$ & $0,0(0)$ & $8,9(8)$ \\
\hline Não Informado & 2 & 3 & 1 & 3 & 12 & 21 \\
\hline \multicolumn{7}{|c|}{ Dia da Semana $(p=0,207)$} \\
\hline Domingo & $21,1(4)$ & $12,5(3)$ & $10,5(2)$ & $26,9(7)$ & $9,1(1)$ & $17,2(17)$ \\
\hline Segunda-feira & $26,3(5)$ & $16,7(4)$ & $15,8(3)$ & $3,8(1)$ & $27,3(3)$ & $16,2(16)$ \\
\hline Terça-feira & $26,3(5)$ & $16,7(4)$ & $0,0(0)$ & $7,7(2)$ & $27,3(3)$ & $14,1(14)$ \\
\hline Quarta-feira & $10,5(2)$ & $20,8(5)$ & $10,5(2)$ & $11,5(3)$ & $0,0(0)$ & $12,1(12)$ \\
\hline Quinta-feira & $0,0(0)$ & $12,5(3)$ & $15,8(3)$ & $11,5(3)$ & $0,0(0)$ & $9,1(9)$ \\
\hline Sexta-feira & $10,5(2)$ & $0,0(0)$ & $10,5(2)$ & $11,5(3)$ & $18,2(2)$ & $9,1(9)$ \\
\hline Sábado & $5,3(1)$ & $20,8(5)$ & $36,8(7)$ & $26,9(7)$ & $18,2(2)$ & $22,2(22)$ \\
\hline Não Informado & 0 & 0 & 1 & 2 & 9 & 12 \\
\hline \multicolumn{7}{|c|}{ Faixa de Horário $(p=0,301)$} \\
\hline 00:00 a 06:59 & $21,1(4)$ & $41,7(10)$ & $31,6(6)$ & $19,2(5)$ & $27,3(3)$ & $28,3(28)$ \\
\hline 07:00 a 11:59 & $31,6(6)$ & $12,5(3)$ & $15,8(3)$ & $15,4(4)$ & $18,2(2)$ & $18,2(18)$ \\
\hline $12: 00$ a $17: 59$ & $0,0(0)$ & $16,7(4)$ & $31,6(6)$ & $30,8(8)$ & $27,3(3)$ & $21,2(21)$ \\
\hline $18: 00$ a $23: 59$ & $47,4(9)$ & $29,2(7)$ & $21,1(4)$ & $34,6(9)$ & $27,3(3)$ & $32,3(32)$ \\
\hline Não Informado & 0 & 0 & 1 & 2 & 9 & 12 \\
\hline
\end{tabular}

Os resultados estão apresentados em frequência relativa (frequência absoluta). Valor de p no teste do qui-quadrado. Fonte: Elaboração própria. 
Tabela 2: Casos de homicídio doloso praticado contra mulheres no âmbito familiar, entre os anos de 2010 e 2014 , de acordo com a faixa etária, cor da pele, região urbana, dia da semana e faixa de horário, registrados em Campo Grande, MS. Campo Grande/MS, 2016.

\begin{tabular}{|c|c|c|c|c|c|c|}
\hline $\begin{array}{l}\text { Homicídio doloso } \\
\text { (Familiar) }\end{array}$ & $\begin{array}{l}2010 \\
(n=4)\end{array}$ & $\begin{array}{l}2011 \\
(n=2)\end{array}$ & $\begin{array}{c}\text { Ano } \\
2012 \\
(n=1)\end{array}$ & $\begin{array}{l}2013 \\
(n=4)\end{array}$ & $\begin{array}{l}2014 \\
(n=4)\end{array}$ & $\begin{array}{l}\text { Total } \\
(15)\end{array}$ \\
\hline \multicolumn{7}{|c|}{ Faixa etária $(p=0,382)$} \\
\hline Menor que 12 & $0,0(0)$ & $0,0(0)$ & $0,0(0)$ & $0,0(0)$ & $0,0(0)$ & $0,0(0)$ \\
\hline Entre 12 e 17 & $0,0(0)$ & $0,0(0)$ & $0,0(0)$ & $0,0(0)$ & $0,0(0)$ & $0,0(0)$ \\
\hline Entre 18 e 25 & $0,0(0)$ & $50,0(1)$ & $0,0(0)$ & $0,0(0)$ & $25,0(1)$ & $13,3(2)$ \\
\hline Maior que 25 & $100,0(4)$ & $50,0(1)$ & $100,0(1)$ & $100,0(4)$ & $75,0(3)$ & $86,7(13)$ \\
\hline \multicolumn{7}{|c|}{ Cor da Pele $(p=0,758)$} \\
\hline Branca & $25,0(1)$ & $50,0(1)$ & $0,0(0)$ & $0,0(0)$ & $25,0(1)$ & $20,0(3)$ \\
\hline Preta & $0,0(0)$ & $0,0(0)$ & $0,0(0)$ & $25,0(1)$ & $0,0(0)$ & $6,7(1)$ \\
\hline Amarela & $0,0(0)$ & $0,0(0)$ & $0,0(0)$ & $0,0(0)$ & $0,0(0)$ & $0,0(0)$ \\
\hline Parda & $75,0(3)$ & $50,0(1)$ & $100,0(1)$ & $75,0(3)$ & $75,0(3)$ & $73,3(11)$ \\
\hline Outras & $0,0(0)$ & $0,0(0)$ & $0,0(0)$ & $0,0(0)$ & $0,0(0)$ & $0,0(0)$ \\
\hline \multicolumn{7}{|c|}{ Região Urbana $(p=0,197)$} \\
\hline Centro & $0,0(0)$ & $0,0(0)$ & $0,0(0)$ & $0,0(0)$ & $0,0(0)$ & $0,0(0)$ \\
\hline Segredo & $0,0(0)$ & $0,0(0)$ & $100,0(1)$ & $25,0(1)$ & $25,0(1)$ & $20,0(3)$ \\
\hline Prosa & $25,0(1)$ & $0,0(0)$ & $0,0(0)$ & $0,0(0)$ & $25,0(1)$ & $13,3(2)$ \\
\hline Bandeira & $0,0(0)$ & $50,0(1)$ & $0,0(0)$ & $0,0(0)$ & $25,0(1)$ & $13,3(2)$ \\
\hline Anhanduizinho & $25,0(1)$ & $0,0(0)$ & $0,0(0)$ & $75,0(3)$ & $25,0(1)$ & $33,3(5)$ \\
\hline Lagoa & $50,0(2)$ & $0,0(0)$ & $0,0(0)$ & $0,0(0)$ & $0,0(0)$ & $13,3(2)$ \\
\hline Imbirussu & $0,0(0)$ & $50,0(1)$ & $0,0(0)$ & $0,0(0)$ & $0,0(0)$ & $6,7(1)$ \\
\hline \multicolumn{7}{|c|}{ Dia da Semana $(p=0,697)$} \\
\hline Domingo & $25,0(1)$ & $0,0(0)$ & $0,0(0)$ & $25,0(1)$ & $0,0(0)$ & $13,3(2)$ \\
\hline Segunda-feira & $25,0(1)$ & $0,0(0)$ & $0,0(0)$ & $0,0(0)$ & $0,0(0)$ & $6,7(1)$ \\
\hline Terça-feira & $0,0(0)$ & $0,0(0)$ & $0,0(0)$ & $25,0(1)$ & $0,0(0)$ & $6,7(1)$ \\
\hline Quarta-feira & $0,0(0)$ & $50,0(1)$ & $0,0(0)$ & $0,0(0)$ & $50,0(2)$ & $20,(3)$ \\
\hline Quinta-feira & $0,0(0)$ & $50,0(1)$ & $100,0(1)$ & $25,0(1)$ & $0,0(0)$ & $20,0(3)$ \\
\hline Sexta-feira & $25,0(1)$ & $0,0(0)$ & $0,0(0)$ & $0,0(0)$ & $25,0(1)$ & $13,3(2)$ \\
\hline Sábado & $25,0(1)$ & $0,0(0)$ & $0,0(0)$ & $25,0(1)$ & $25,0(1)$ & $20,0(3)$ \\
\hline \multicolumn{7}{|c|}{ Faixa de Horário $(p=0,249)$} \\
\hline 00:00 a 06:59 & $25,0(1)$ & $50,0(1)$ & $0,0(0)$ & $0,0(0)$ & $0,0(0)$ & $13,3(2)$ \\
\hline 07:00 a 11:59 & $50,0(2)$ & $0,0(0)$ & $100,0(1)$ & $25,0(1)$ & $0,0(0)$ & $26,7(4)$ \\
\hline $12: 00$ a $17: 59$ & $0,0(0)$ & $50,0(1)$ & $0,0(0)$ & $0,0(0)$ & $25,0(1)$ & $13,3(2)$ \\
\hline $18: 00$ a $23: 59$ & $25,0(1)$ & $0,0(0)$ & $0,0(0)$ & $75,0(3)$ & $75,0(3)$ & 46,7 (7) \\
\hline
\end{tabular}

Os resultados estão apresentados em frequência relativa (frequência absoluta). Valor de p no teste do quiquadrado.

Fonte: Elaboração própria. 
Tabela 3: Casos de lesão corporal causada em mulheres no âmbito familiar, entre os anos de 2010 e 2014 , de acordo com a faixa etária, cor da pele, região urbana, dia da semana e faixa de horário, registrados em Campo Grande, MS. Campo Grande MS, 2016.

\begin{tabular}{|c|c|c|c|c|c|c|}
\hline $\begin{array}{l}\text { Lesão corporal } \\
\text { (Familiar) }\end{array}$ & $\begin{array}{c}2010 \\
(\mathrm{n}=1.252) \\
\end{array}$ & $\begin{array}{c}2011 \\
(\mathrm{n}=1.355) \\
\end{array}$ & $\begin{array}{c}\text { Ano } \\
2012 \\
(\mathbf{n}=1.323) \\
\end{array}$ & $\begin{array}{c}2013 \\
(\mathrm{n}=1.193) \\
\end{array}$ & $\begin{array}{c}2014 \\
(\mathrm{n}=1.507) \\
\end{array}$ & $\begin{array}{l}\text { Total } \\
(6.630)\end{array}$ \\
\hline \multicolumn{7}{|c|}{ Faixa etária $(p=0,218)$} \\
\hline Menor que 12 & $1,1(14)$ & $0,6(8)$ & $1,1(14)$ & $1,2(14)$ & $1,3(20)$ & $1,1(70)$ \\
\hline Entre 12 e 17 & $4,8(60)$ & $4,6(63)$ & $6,2(82)$ & $6,7(80)$ & $6,5(98)$ & $5,8(383)$ \\
\hline Entre 18 e 25 & $28,3(354)$ & $30,7(416)$ & $28,7(380)$ & $27,9(333)$ & $28,4(428)$ & $28,8(1911)$ \\
\hline Maior que 25 & $65,8(824)$ & $64,1(868)$ & $64,0(847)$ & $64,2(766)$ & $63,8(961)$ & $64,3(4266)$ \\
\hline \multicolumn{7}{|c|}{ Cor da Pele $(p=0,487)$} \\
\hline Branca & $31,9(338)$ & 34,7 (393) & $32,4(363)$ & $30,9(308)$ & $32,1(400)$ & $32,4(1802)$ \\
\hline Preta & $3,0(32)$ & $3,4(38)$ & $3,5(39)$ & $2,4(24)$ & $3,3(41)$ & $3,1(174)$ \\
\hline Amarela & $0,1(1)$ & $0,1(1)$ & $0,1(1)$ & $0,4(4)$ & $0,2(2)$ & $0,2(9)$ \\
\hline Parda & $64,8(686)$ & $61,9(701)$ & $64,1(718)$ & $66,3(660)$ & $64,4(803)$ & $64,2(3568)$ \\
\hline Outras & $0,1(1)$ & $0,0(0)$ & $0,0(0)$ & $0,0(0)$ & $0,0(0)$ & $0,0(1)$ \\
\hline Não Informado & 194 & 222 & 202 & 197 & 266 & 1081 \\
\hline \multicolumn{7}{|c|}{ Região Urbana $(p=0,175)$} \\
\hline Centro & $7,3(79)$ & $6,8(78)$ & $5,9(65)$ & $6,8(68)$ & $6,1(78)$ & $6,6(368)$ \\
\hline Segredo & $15,1(164)$ & $16,0(184)$ & $18,5(204)$ & $18,0(179)$ & $16,7(212)$ & $16,8(943)$ \\
\hline Prosa & $9,7(105)$ & $10,8(124)$ & $10,7(118)$ & $9,7(97)$ & $9,8(124)$ & $10,1(568)$ \\
\hline Bandeira & $14,6(158)$ & $16,0(185)$ & $13,9(153)$ & 13,9 (139) & $15,9(202)$ & $14,9(837)$ \\
\hline Anhanduizinho & $24,3(263)$ & $24,0(277)$ & $25,5(281)$ & $28,9(288)$ & $26,9(342)$ & $25,9(1451)$ \\
\hline Lagoa & $17,3(188)$ & $14,8(171)$ & $14,2(157)$ & $12,7(127)$ & $14,9(190)$ & $14,9(833)$ \\
\hline Imbirussu & $11,7(127)$ & $11,6(134)$ & $11,3(125)$ & $9,9(99)$ & $9,7(123)$ & $10,8(608)$ \\
\hline Não Informado & 168 & 202 & 220 & 196 & 236 & 1022 \\
\hline \multicolumn{7}{|c|}{ Dia da Semana $(p=0,105)$} \\
\hline Domingo & $25,0(293)$ & $24,3(302)$ & $28,3(341)$ & $25,8(284)$ & $21,9(307)$ & $24,9(1527)$ \\
\hline Segunda-feira & $11,5(135)$ & $10,9(135)$ & $11,1(134)$ & $9,5(104)$ & $11,5(161)$ & $10,9(669)$ \\
\hline Terça-feira & $10,2(119)$ & $9,3(115)$ & $9,7(117)$ & $11,4(125)$ & $10,0(141)$ & $10,1(617)$ \\
\hline Quarta-feira & $9,7(113)$ & $11,6(144)$ & $10,7(129)$ & $9,8(108)$ & $10,7(151)$ & $10,5(645)$ \\
\hline Quinta-feira & $10,5(123)$ & $10,2(127)$ & $9,9(119)$ & $9,3(102)$ & $11,5(162)$ & $10,3(633)$ \\
\hline Sexta-feira & $12,6(148)$ & $11,1(138)$ & $11,9(144)$ & $11,2(123)$ & $12,6(177)$ & $11,9(730)$ \\
\hline Sábado & $20,5(240)$ & $22,6(280)$ & $18,5(223)$ & $23,0(253)$ & $21,8(306)$ & $21,3(1302)$ \\
\hline Não Informado & 81 & 114 & 116 & 94 & 102 & 507 \\
\hline \multicolumn{7}{|c|}{ Faixa de Horário $(p=0,890)$} \\
\hline 00:00 a 06:59 & $17,6(206)$ & $17,4(216)$ & $19,1(230)$ & $16,7(184)$ & $17,4(245)$ & $17,7(1081)$ \\
\hline 07:00 a 11:59 & $13,9(163)$ & $14,7(183)$ & $15,0(181)$ & $13,9(153)$ & $13,3(187)$ & $14,2(867)$ \\
\hline $12: 00$ a $17: 59$ & $20,8(243)$ & $21,5(267)$ & $21,6(261)$ & $22,2(244)$ & $22,6(317)$ & $21,8(1332)$ \\
\hline $18: 00$ a $23: 59$ & $47,7(559)$ & $46,3(575)$ & $44,3(535)$ & $47,1(518)$ & 46,7 (656) & $46,4(2843)$ \\
\hline Não Informado & 81 & 114 & 116 & 94 & 102 & 507 \\
\hline
\end{tabular}

Os resultados estão apresentados em frequência relativa (frequência absoluta). Valor de $\mathrm{p}$ no teste do quiquadrado. Letras diferentes na linha indicam diferença significativa entre os anos de estudo (teste do quiquadrado, $\mathrm{p}<0,05$, com correção de Bonferroni).

Fonte: Elaboração própria. 
Na Figura 5, verifica-se que nas regiões urbanas mais violentas, Segredo e Anhanduizinho respectivamente, têm 14 Unidades de Saúde, 20 Unidades de Assistência Social, uma Unidade da Polícia Civil e 22 Unidades de Saúde, 38 Unidades de Assistência Social e uma Unidade da Polícia Civil. Dessa forma, verifica-se que por mais que essas regiões apresentem maior número de casos de violência doméstica as mesmas apresentam uma abrangência de rede de apoio melhor comparada às outras regiões da cidade.

Figura 5: Mapa de distribuição especial dos registros de violência doméstica e das unidades de serviços (Delegacias de Polícia Civil, Casa da Mulher Brasileira, Unidades de Assistência Social, Unidades de Saúde, Terminais de Transporte Coletivo) por regiões urbanas, Campo Grande/MS, 2016 (imagens Google, 2016; shape de limites de regiões: PMCG, 2015).

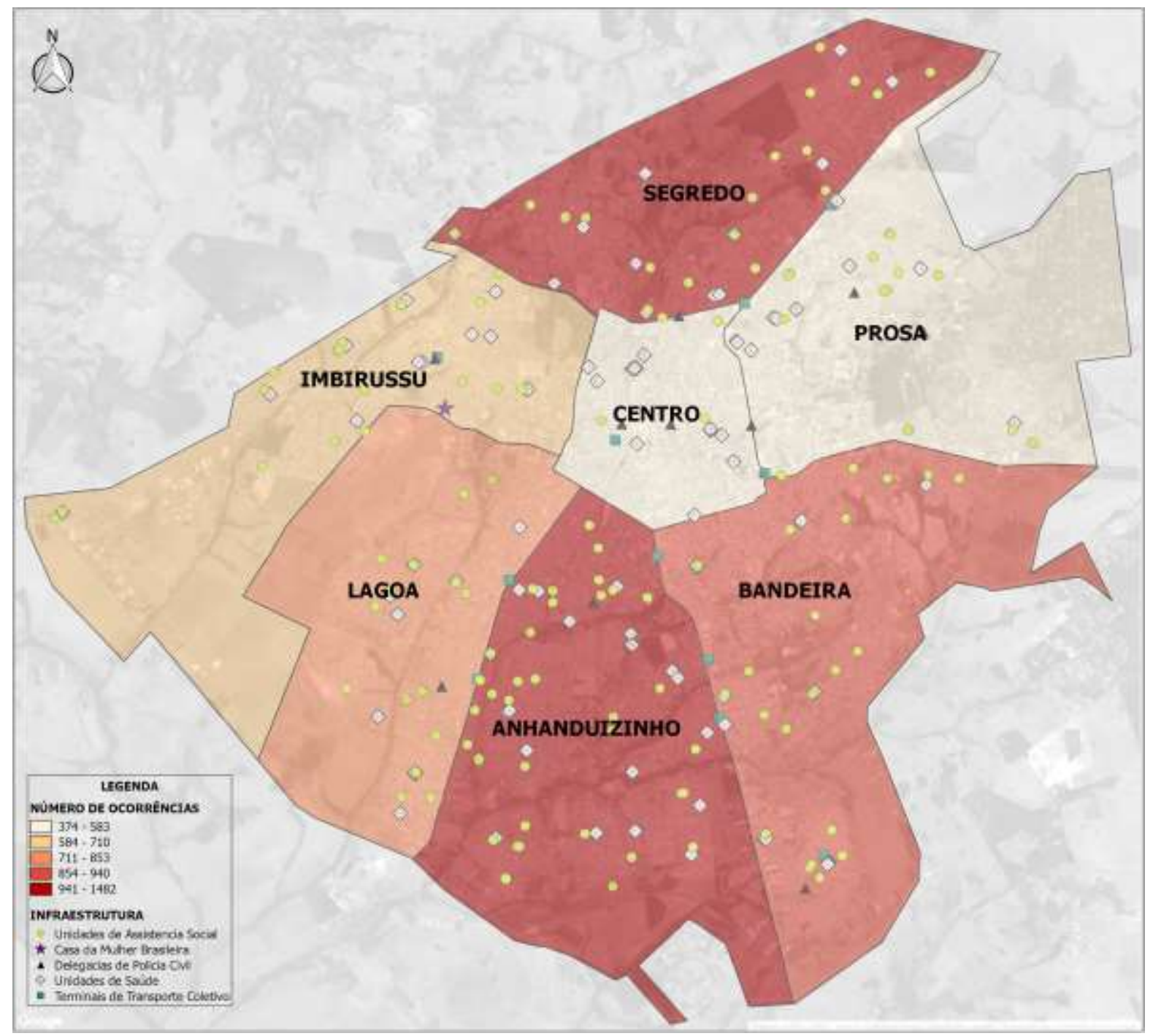

Fonte: Elaboração própria.

\section{Discussão}

Este estudo evidenciou que dos 11.084 casos de lesões corporais notificados 59,8\% foram registrados no âmbito intrafamiliar. Com relação aos estupros e homicídios ocorridos no contexto familiar houve uma maior incidência de casos em mulheres pardas e com mais de 25 anos. Os bairros mais violentos da capital de MS são os mais distantes e com mais unidades de rede de apoio social e de tratamento de saúde. 
A violência contra a mulher no âmbito familiar prevaleceu em mais da metade dos casos nesta pesquisa, quando comparada à violência em geral. Waiselfisz (2015), em seu estudo, utilizou como fonte de dados o Sinan e obteve resultados semelhantes aos nossos, além de ter identificado que $67,2 \%$ dos responsáveis pela agressão eram parentes, imediatos, parceiros ou ex-parceiros das mulheres. Estudo transversal realizado em Arcoverde, Pernambuco (PE) entre os anos de 2011 e 2016, por meio da análise dos inquéritos criminais do tribunal de justiça, cujo objetivo era coletar dados para analisar o perfil sociodemográfico e as agressões sofridas por mulheres em situação de violência física, revelou que a média de idade das vítimas era de 27 anos, com ensino fundamental incompleto, sendo a maioria dos agressores homens e companheiros delas (Moreira et al., 2018).

A violência mais empregada pelos homens está relacionada à força física, para afirmar o seu poder sobre a mulher (Gregoleti; de Paula \& Kodato, 2016). Neste estudo, as agressões físicas foram o tipo de violência mais frequente perpetrada em domicílio, corroborando os dados encontrados nos estudos de Silva; Oliveira (2016), sobre a violência doméstica no Distrito Federal (DF) em que a agressão física foi a mais notificada no período de 2009-2012, correspondendo a 46,8\%, seguida por violência sexual $22,5 \%$.

Estudo epidemiológico realizado em Vitória, Espírito Santo (ES) de março a setembro de 2014 em 26 unidades de saúde que apresentavam Estratégia da Saúde da Família (ESF) e/ou Programa de Agentes Comunitários de Saúde (PACS), cujo objetivo era estimar a prevalência e os fatores associados à violência praticada por parceiro íntimo, ao longo da vida, entre as usuárias da Atenção Primária à Saúde, (APS) demonstrou que o tipo de violência mais prevalente foi a violência psicológica $57,6 \%$ seguida da violência física 39,3\% e a violência sexual 18,0\%. Outro dado importante deste estudo é que as mulheres com até oito anos de estudo, divorciadas, cujas mães sofreram VPI, que relataram uso de drogas e vivenciaram a violência sexual na infância apresentaram maiores prevalências das três violências. Além disso, a religião evangélica esteve associada às violências psicológica e sexual e o uso de cigarro às violências física e psicológica (Santos, et al., 2020).

Como exposto anteriormente, no presente estudo, o estupro foi um dos tipos de violência doméstica com maior ocorrência em Campo Grande, MS, nos anos de 2010 a 2014. Segundo o Fórum brasileiro de segurança pública (2016), o estado de MS, no ano de 2015, ocupou o segundo lugar em casos de estupro dentre os estados do Brasil, perdendo apenas para o Acre (BRASIL, 2016), demonstrando que a ocorrência deste tipo de violência está presente na capital e em outros municípios de MS. Além de que pode haver subnotificação, pois, para Sousa (2017), a falta de conhecimento sobre o conceito do estupro dificulta que o crime seja registrado, que a condição da vítima seja reconhecida e devidamente remediada.

Estrela et al. (2016) denotam que a construção social da visão de inferioridade e submissão das mulheres mantém enraizada a aceitação da violência contra a mulher devido à desigualdade entre os sexos. Desta maneira, existe a culpabilização da mulher vítima de estupro, sugerindo que a mesma tenha provocado o ato de violência, o que desfoca a culpa do agressor, sendo vista por muitos como algo normal e natural, firmando assim, a superioridade do homem em relação à mulher contribuindo para a manutenção de uma sociedade machista (Santos, et al., 2020).

Estudo realizado no Rio Grande do Sul (RS), que objetivou analisar a tendência temporal e as características dos casos notificados de estupro, registrados no estado do RS, entre os anos de 2009 a 2017, demonstrou que o estupro foi a principal violência doméstica notificada e mais prevalente no sexo feminino 83,71\%, menores de 14 anos 64,37\%, com ensino fundamental incompleto $46,79 \%$ e de raça branca $74,26 \%$. Além disso, este estudo evidenciou que as notificações de estupro no RS cresceram de forma significativa ao longo dos nove anos analisados (Santos, et al., 2020).

Os feminicídios são a manifestação máxima da violência contra a mulher. No atual estudo, o homicídio doloso foi o segundo tipo de violência mais frequente no âmbito familiar entre os anos de 2010 e 2014. Dessa maneira, o feminicídio é definido como um crime de ódio contra as mulheres, os assassinatos estão na maioria das vezes presentes no contexto de 
violência intrafamiliar e os crimes envolvem a destruição da identidade da vítima e de sua condição de mulher (Brito filho, et al., 2017).

Pesquisa ecológica com o objetivo de analisar a relação entre feminicídios com uma série de indicadores em cidades brasileiras com mais de 400 mil habitantes referente aos anos de 2007 e 2009 e de 2011 a 2013 evidenciou que ocorreram 4.368 óbitos femininos por agressão entre os anos de 2007 a 2009 e 4.834 entre os anos de 2011 a 2013, nos 58 municípios brasileiros estudados, representando aumento de 10\% entre os dois triênios (Meneghel, 2016). Segundo Meneghel e Lerma (2017), as taxas ascendentes de feminicídios demonstram a necessidade de enfrentamento e não basta usar as questões de gênero ou a proteção legal. É necessária uma luta política com o entendimento das inter-relações entre os determinantes patriarcais, racistas, capitalistas e coloniais.

Predominaram no presente estudo a ocorrência da violência aos finais de semana e no período noturno. Fato que corrobora com os achados do estudo realizado por Garcia et al. (2016) que objetivou identificar fatores associados ao atendimento por violência doméstica e familiar entre vítimas atendidas em serviços de urgência e emergência no Brasil, tratouse de um estudo de casos e controles baseado no Sistema de Vigilância de Violências e Acidentes (VIVA). Assim, os autores evidenciaram a ocorrência de violência entre jovens (18-29 anos), com baixa escolaridade, que não exerciam atividade remunerada, que consumiam bebida alcoólica, ocorrência aos finais de semana e durante a noite ou madrugada. Dessa maneira, os fatores associados à ocorrência da violência doméstica, no período noturno e aos finais de semana, estão relacionados ao contato mais frequente da vítima com o agressor e é neste período que a pessoas costumam aumentar o consumo de álcool.

A região urbana do Anhanduizinho apresentou o maior número de ocorrência de casos registrados de violência doméstica neste estudo. $\mathrm{O}$ ambiente sem desenvolvimento socioeconômico interfere no grau de felicidade e satisfação do ser humano e a violência surge quando as áreas são conflituosas e existe uma desigualdade social evidente (Ribeiro; Silva \& Silva, 2015). Outro fator que influencia na decisão de registrar a violência diz respeito à logística das regiões mais periféricas por estarem distantes dos locais de assistência social, legal e de saúde e pela dificuldade financeira (Ribeiro \& Silva, 2015).

Pesquisa epidemiológica realizado em Vitória (ES), em unidades saúde com mulheres de 20 a 59 anos usuárias da APS, revelou que as participantes de menor renda familiar tiveram maiores prevalências de violência física (Leite, et al., 2017). Fato semelhante evidenciado no estudo documental realizado em Teresina (PI), cuja amostra foi composta por 120 prontuários referente aos atendimentos realizados entre 2017 e 2018 no Centro de referência da mulher em situação de violência Esperança Garcia, em que as mulheres que sofreram violência estavam desempregadas 42.5\% (Santana, et al., 2020).

Investigação realizada por Leite et al. (2021) constatou que mulheres com menos de nove anos de estudos tiveram uma prevalência de $62 \%$ de VPI, quando comparadas as mulheres com 12 anos ou mais de estudos. O ambiente sem desenvolvimento socioeconômico interfere no grau de felicidade e satisfação do ser humano e a violência surge quando as áreas são conflituosas e existe uma desigualdade social evidente (Ribeiro; Silva \& Silva, 2015).

Pesquisa qualitativa realizada com 26 profissionais que atuavam no enfrentamento da violência contra mulheres em municípios no interior do Rio Grande do Sul (RS) evidenciou que a distância, o acesso restrito ao transporte e a dependência do marido foram considerados pelos participantes como fatores que dificultam a acessibilidade da mulher à rede de atenção à saúde, segurança e justiça. Segundo os mesmos autores, quando a mulher precisa esperar pelo transporte público, fica desestimulada a procurar os serviços da rede e muitas vezes acaba se reconciliando com agressor (Costa et al., 2017). Existem poucas delegacias de proteção à mulher no país, são 400 unidades para mais de 5,5 mil municípios (Silva \& Krohling, 2019). Além disso, uma revisão realizada com 22 artigos de 1981 até 2014 revelou que o consumo de álcool aumenta o comportamento agressivo do homem em relação à mulher.

Pesquisa realizada com o objetivo de indicar determinantes socioeconômicos que influenciam o nível de felicidade dos indivíduos com a participação de quatro bairros da região do Anhanduizinho: Aero Rancho, Piratininga, Los Angeles e 
Centro-Oeste demonstrou que para os participantes do estudo a renda não influencia no nível de felicidade e sim, a idade, nível de escolaridade, se o indivíduo nasceu no Estado de Mato Grosso do Sul e se é ou não viúvo (Aydos, Figueiredo Neto \& Teixeira, 2017).

Quando às mulheres em situação de violência decidem romper com esse ciclo e desejam registrar queixas em uma delegacia, vivenciam o paradoxo de sofrer ao relembrar dos fatos, tornar público algo que é intimo, sendo que o intuito não é a separação de seus parceiros, pois acreditam que os mesmos poderão mudar de atitudes com as advertências verbais da autoridade policial (Gregoleti; de Paula; Kodato, 2016).

Evidenciou-se no presente estudo que ainda há escassez de serviços da rede de apoio às mulheres em situação de violência doméstica nas regiões urbanas. Resultados semelhantes foram encontrados por Tavares et al. (2016) que, ao analisarem a relação das taxas de homicídio com a qualidade ao acesso de serviços, como o de segurança pública em Betim, Minas Gerais (MG) no ano de 2006 a 2011, verificaram que existe uma relação direta entre o aumento do coeficiente das taxas de homicídio com a vulnerabilidade social. Batista et al. (2016) correlacionaram a ausência da DEAM na região de Águas Lindas de Goiás (GO) com o aumento dos casos de estupro na referida área, durante o período de janeiro de 2012 a outubro de 2013.

Com relação às instituições de saúde, percebe-se que a assistência prestada à mulher em situação de violência doméstica pelos profissionais de saúde é carente de habilidades técnicas e científicas, pois o medo do agressor é algo que ultrapassa o ambiente de trabalho. Além disso, é evidenciado o receio e o medo do julgamento dos demais colegas, o que acaba por desencadear a invisibilidade das mulheres em situação de violência. Sabe-se que a equipe de enfermagem, por permanecer mais tempo ao lado das pacientes, pode identificar situações de violência, contribuindo para a quebra do silêncio da mulher, por meio de orientação sobre os serviços de apoio (Acosta, et al., 2018).

As limitações da pesquisa referem-se a fontes de dados serem secundárias, ao tempo decorrido da coleta de dados e à falta de acesso direto aos dados, o que garantiria maior fidelidade na coleta destes, bem como a obtenção de mais variáveis para aprofundamento do conhecimento sobre a violência em Campo Grande, como a escolaridade, renda familiar, ocupação da mulher, grau de parentesco e perfil do agressor. Os itens não informados nos resultados evidenciam a não padronização do preenchimento dos boletins de ocorrência, dificultando a obtenção de informações importantes para a execução de determinadas ações.

\section{Conclusão}

Quanto ao tipo de violência doméstica contra a mulher identificada mais frequente está a lesão corporal; quanto à idade e à cor da pele autorreferida, as mulheres com mais de 25 anos e pardas foram as que mais sofreram violência doméstica; ocorreram nas regiões urbanas do Anhanduizinho e do Segredo, prevalecendo aos finais de semana e no período noturno. Desse modo, a distribuição espacial dos casos de violência doméstica contra a mulher e das unidades de apoio ao enfrentamento da violência, de acordo com as regiões urbanas de Campo Grande/MS, permitiu verificar a predominância da violência nas regiões urbanas com alta densidade populacional e de baixa renda, evidenciando relação entre a violência com as questões socioeconômicas.

Sabe-se que as regiões urbanas do Anhanduizinho e do Segredo possuem uma rede de apoio de enfrentamento à violência melhor que outras regiões, mas ainda precária, considerando a frequência elevada de ocorrência dos casos de violência. Os resultados oriundos da distribuição espacial da ocorrência dos casos de violência doméstica nas regiões urbanas de Campo Grande/MS e de suas unidades de apoio permitiram identificar as regiões mais vulneráveis, que necessitam de maior intervenção da gestão pública. 
Considerando que a violência contra a mulher é um problema de saúde pública e que, para o seu enfrentamento faz-se necessária a articulação entre os diversos setores da sociedade, a presença dos profissionais de saúde neste cenário propiciaria um atendimento mais abrangente e resolutivo, como a avaliação dessas mulheres e a agilização dos encaminhamentos aos serviços de saúde quando necessário. Entre os profissionais de saúde, o enfermeiro encontra-se em uma posição chave, seja pela proximidade com a clientela na APS com a utilização da Consulta de Enfermagem, possibilitando o reconhecimento dos casos de violência ou nos hospitais por ser líder da equipe, contribuindo com a articulação dos encaminhamentos e condutas devidas.

Estudos futuros sobre a violência contra a mulher são necessários para melhor compreensão de suas causas e para a elaboração de estratégias que permitam uma melhor articulação entre os serviços de saúde, social e de justiça, em parceria com diversos órgãos federais, municipais e estaduais, assim como para que propostas sobre o direcionamento dos recursos públicos para as regiões mais vulneráveis sejam sugeridas e efetivadas.

\section{Referências}

Acosta, D. F., Gomes, V. L. O., Oliveira, D. C., Marques S. C., Fonseca A. D. (2018) . Representações sociais de enfermeiras acerca da violência doméstica contra a mulher: estudo com abordagem estrutural. Revista Gaúcha de Enfermagem, 39: e 61308.

Amarijo, C. L., Figueira, A. B., Ramos, A. M., \& Minasi, A. S. A. (2020). Relações de poder nas situações de violência doméstica contra a mulher: tendência dos estudos. Revista Cuidarte, 11(2): e1052.

Aydos, L. R., Figueiredo Neto, L. F., \& Teixeira, W. M. (2017). Análise dos determinantes do nível de felicidade subjetiva: uma abordagem local. Interações, Campo Grande, MS, 18(1): 137-150.

Batista, A. S., França, K. C. B., Berdet, M., \& Pinto, M. A. B. (2016). Metropolização, homicídios e segurança pública na área metropolitana de Brasília: o município de Águas Lindas de Goiás. Sociedade e Estado [online]. 31(2): 433-457.

Brasil. (2006). Lei n ${ }^{\circ} 11.340$, de 7 de agosto de 2006. Cria mecanismos para coibir a violência doméstica e familiar contra a mulher e dispõe sobre a criação dos Juizados de Violência Doméstica e Familiar contra a mulher. Brasília.

Brasil. (2016). Fórum Brasileiro de Segurança Pública. Anuário Brasileiro de Segurança Pública. <http://www.forumseguranca.org.br/storage/10_anuario_site_18-11-2016-retificado.pdf>

Brito -filho, C. M. (2017). Violência de gênero - Feminicídio. Cadernos de Direito, Piracicaba, v. 17(32): 179-195. ISSN Impresso: 1676-529-X.

Campos, B., Tchalekian, B., \& Paiva, V. (2020). Violência contra a mulher: vulnerabilidade programática em tempos de sars-cov-2/ covid-19 em São Paulo. Psicologia \& Sociedade 32: e020015.

Costa, M. C. et al. (2017). Mulheres rurais e situações de violência: fatores que limitam o acesso e a acessibilidade à rede de atenção à saúde. Revista Gaúcha de Enfermagem. 38(2), e59553. <https://doi.org/10.1590/1983-1447.2017.02.59553>.

Crane, C. A., Godleski, S. A., Przybyla, S. M., Schlauch, R. C., \& Testa, M. (2016). Os efeitos proximais do consumo agudo de álcool na agressão entre homens e mulheres: uma revisão meta-analítica da literatura experimental. Security Dialogue. 17 (5), 155-171. <https://doi.org/10.1177/0967010604044974>

Estrela, F. M., Gomes, N. P., Gusmão, M. E. N., et al. (2016). Demographic or socio-demographic aspects of women in domestic violence situations: a descriptive study. Online Brazilian Journal of Nursing 15(3): 423-432.

Garcia, L. P., Duarte, E. C., de Freitas, L. R. S, \& da Silva, D. M. S. (2016). Violência doméstica e familiar contra a mulher: estudo de casos e controles com vítimas atendidas em serviços de urgência e emergência. Caderno Saúde Pública, 32(4): e00011415.

Gregoleti, A. F. M., Paula, A. S., \& Kodato, S. (2016). Violência doméstica: significado e representações construídas por mulheres vitimizadas. Perspectivas em Psicologia, 20(2), 48-64.

IBGE. Instituto Brasileiro de Geografia e Estatística. Cidades. Mato Grosso do Sul. Campo Grande, (2019). https://cidades.ibge.gov.br/brasil/ms/campogrande/panorama.

Leite, F. M. Costa et al. (2017). Violence against women, Espírito Santo, Brazil. Revista de Saúde Pública 51 33. <https://doi.org/10.1590/S15188787.2017051006815>

Leite, F. M. C. et al. (2021). Associação entre a violência e as características socioeconômicas e reprodutivas da mulher. Cadernos Saúde Coletiva 29(2), 279289. https://doi.org/10.1590/1414-462X202129020387>.

Lucena, K. D. T., Vianna, R. P. T., Nascimento, J. A., Campos, H. F. C., \& Oliveira, E. C. T. (2017). Association between domestic violence and women's quality of life. Revista Latino-Americana de Enfermagem. 25:e2901.

Mascarenhas, M. D. M., Tomaz, G. R.., Meneses, G. M. S., Rodrigues, M. T. P., Pereira, V. O. M., \& Corassa, R. B. (2020). Análise das notificações de violência por parceiro íntimo contra mulheres, Brasil, 2011-2017. Revista Brasileira de Epidemiologia. 23(1): 1-13. 
Meneghel, S. N., Rosa, B. A., Ceccon, RF, Hirakata, V. N., \& Danilevicz, I. M. (2016). Feminicídios: estudo em capitais e municípios brasileiros de grande porte populacional. ciência \& saúde coletiva: http://www.cienciaesaudecoletiva.com.br/artigos/feminicidios-estudo-em-capitais-e-municipios-brasileiros-degrande-porte-populacional/15473?id=15473

Meneghel, S. N., \& Lerma, B. R. L. (2017). Feminicídios em grupos étnicos e racializados: síntese. Ciência \& Saúde Coletiva, 22(1): 117-122.

Moreira, M. H. B. A., Maurício, H. A., \& Vidal, H. G. (2018). Violência física contra a mulher sertaneja: perfil sociodemográfico em Arcoverde-PE, Brasil. Revista do Laboratório de Estudos da Violência da UNESP/Marília. Edição 22. ISSN 1983-2192.

PLANURB. (2016). Instituto Municipal de Planejamento Urbano. Perfil Socioeconômico. (2016). Campo Grande, Mato Grosso do Sul. Prefeitura municipal de Campo Grande, 23 ed.

Reis, D. M., Prata, L. C. G., \& Cláudia Regina Parra, C. R. (2018). Psicologia. Pt.

Ribeiro, M. I. C., Silva, R. D., \& Silva, M. G. S. N. (2015). Criminalidade e espaço: uma representação espacial dos crimes de violência contra a mulher no município de Porto Velho-Rondônia. Revista Presença Geográfica, 2(1): 56-66.

Ribeiro, M. I. C., \& Silva, M. G. S. N. (2015). Violência, Vulnerabilidade e Desigualdade Sócioespacial: análise das dificuldades enfrentadas pelas mulheres vítimas de violência doméstica na área urbana de Porto Velho-RO. Revista Latino-americana de Geografia e Gênero, 6(2): 92-104.

Santana, R. da S., Sousa, F. K. B de., Silva, Í. A., Simão, E. S. S., Costa, G. O. P da., Jansen, R. C. S., Araújo, D. M. M de., Silva, C. de K.C da., Veloso, V.R.., \& Santos, M. O dos. (2020). Violência contra a mulher: caracterização dos casos em acompanhamento de um centro de referência municipal. Research, Society and Development, 9(11): e98291110574.

Santos, F. K. L., Pessoa, B. G. F., da Silva, R. A., Silva, L. D., Araújo, N. J. C., do Monte, L. M. I., \& Nascimento, E. F. (2020). Cultura do estupro: o machismo manifesto nas paradas musicais. Research, Society and Development, 9(7): e370974097.

Santos, G. K., Bartsch, L., Schuster, M. E. A., Pioczkoski, N. P., Zancan, S., \& Jantsch, J. B. (2020). Caracterização e tendência temporal das notificações de violência sexual no Rio Grande do Sul. Research, Society and Development, 9(8): e277985796.

Santos, I. B., Leite, F. M. C., Amorim, M. H. C., Maciel, P. M. A., \& Gigante, D. P. (2020). Violência contra a mulher na vida: estudo entre usuárias da Atenção Primária. Ciênc. saúde coletiva 25(5):1935-1946.

Sardenberg, C. M B., \& Tavares, M. S. (2016). Violência de gênero contra mulheres: suas diferentes faces e estratégias de enfrentamento e monitoramento EDUFBA, Bahianas collection,. 19: 335.

Schek, G., Silva M. R. S., Lacharité, C., Cézar-Vaz, M. R., Bueno, M. E. N., \& Ventura, J. (2018). Práticas profissionais que silenciam a violência intrafamiliar contra crianças e adolescentes. Texto Contexto Enfermagem. 27(1):e1680016.

Silva, A. F. C., Alves, C. G., Machado, G. D., Meine, I. R., Silva, R. M., \& Carless, J. P. P. (2020). Violência doméstica contra a mulher: contexto sociocultural e saúde mental da vítima. Research, Society and Development, 9(3): e35932363.

Silva, L.E.L. \& Oliveira, M.L.C. (2016) Características epidemiológicas da violência contra a mulher no Distrito Federal, 2009 a 2012. Epidemiologia e Serviços de Saúde, 25(2): 331-342.

Sousa, R. F. (2017). Cultura do estupro: prática e incitação à violência sexual contra mulheres. Estudos Feministas, 25(1): 9-29.

Souza, V. M. P., Larocca, L. M., Chaves, M. M. N., Fialla, M. R. P. M., Durand, M. K., \& Lourenço, R. G. (2021). Violência de gênero no espaço universitário. Cogitare Enfermagem, 26: e67689.

Silva, T. M., Krohling, A. (2019). Acesso à Justiça para Mulheres em Situação de Violência Análise da Atuação da Delegacia da Mulher à Luz da Justiça Social Pautada na Ética da Alteridade e na Responsabilidade. 7(13). ISSN 2317-5389.

Tavares, R., Catalan, V. D. B., Romano, P. M. M., Melo, E. M. (2016). Homicídios e vulnerabilidade social. Ciência \& Saúde Coletiva. 21 (3): 923-934.

Waiselfisz, J. J. (2015). Mapa da violência 2015: homicídio de mulheres no Brasil. CEBELA/FLACSO. <http://www.mapadaviolencia.org.br/pdf2015/MapaViolencia_2015_mulheres.pdf >

World Health Organization. (2021). Global, regional and national prevalence estimates for intimate partner violence against women and global and regional prevalence estimates for non-partner sexual violence against women. 